\title{
Dynamics of trapped adult populations of Drosophila suzukii Matsumura (Diptera: Drosophilidae) and its parasitoids in Uşak Province, Turkey
}

\author{
Erdal Zengin ${ }^{1^{*}}$ (D) and Issmail Karaca ${ }^{2}$ (D)
}

\begin{abstract}
The spotted wing drosophila fly, Drosophila suzukii (Matsumura, 1931) (Diptera: Drosophilidae), is a pest which caused serious crop losses to soft-skinned fruits such as cherries, strawberries, and grapes. In this study, population dynamics of D. suzukii and its associated parasitoids were investigated. The surveys were conducted at one location of Uşak province, Turkey, between April and December of 2017 and 2018. For this purpose, the baited traps were weekly hung on the fruit trees. Population of D. suzukii in 2017 and 2018 peaked at the end of October and in mid-November, respectively. Moreover, three parasitoid species, namely, Leptopilina heterotoma (Thomson, 1862), Ganaspis xanthopoda (Ashmead, 1896) (Hymenoptera: Figitidae), and Pachycrepoideus vindemiae (Rondani, 1875) (Hymenoptera: Pteromalidae), were identified associated with the pest. Among these, G. xanthopoda and L. heterotoma are new records for Turkey Eucoilinae fauna. P. vindemiae was the most abundant parasitoid in both years, while G. xanthopoda was detected only in 2017. This study is the first research to detect parasitoids of D. suzukii in Turkey.
\end{abstract}

Keywords: Traps, Drosophila suzukii, Figitidae, New record, Parasitoids

\section{Background}

The spotted wing drosophila fly, Drosophila suzukii (Matsumura) (Diptera: Drosophilidae), is an invasive species that can lay eggs in intact soft-skinned fruits by their advanced ovipositor (Yu et al. 2013; Ioriatti et al. 2015). The larval feeding in fruits causes softness and fruit dropping (Stacconi et al. 2013). Furthermore, oviposition wounds caused by fruits provide a suitable environment for secondary infections (Haye et al. 2016). It was reported that revenue loss in Italy in 2011 due to D. suzukii damage was about 3 million Euros (De Ros et al. 2013). The pest generally prefers cherries, peaches, strawberries, and grapes as host (Walsh et al. 2011). These crops constitute 12.7\% of fresh fruits and vegetables exports of Turkey, which corresponds to an export value of about $\$ 450$ million. The presence of the pest in Turkey was firstly detected by Orhan et al. (2016) at the end of September 2014 on

\footnotetext{
* Correspondence: 0erdalzengin0@gmail.com

'Directorate of Provincial Agriculture and Forestry, 64100 Uşak, Turkey Full list of author information is available at the end of the article
}

strawberry fruits in Erzurum province, and thereafter Efil (2018) reported recorded it in Çanakkale province.

Insecticide usage has been the most preferred method against D. suzukii (Haye et al. 2016). However, the efficiency of the agricultural chemicals may be reduced by abundance of non-crop hosts which can serve as feeding and breeding alternative sites for the pest and their abilities to quickly move (Lee et al. 2015). As the natural enemies can reproduce in both cultivated and uncultivated habitats, they play an important role rather than the pesticides for declining the pest populations (Haye et al. 2016).

In the studies conducted so far on the natural enemies of D. suzukii, 4 genera belonging to 3 families have been recognized as parasitoid species: Leptopilina, Ganaspis (Hymenoptera: Figitidae), Trichopria (Hymenoptera: Diapriidae), and Pachycrepoideus (Hymenoptera: Pteromalidae) (Cini et al. 2012). Leptopilina and Ganaspis are larval parasitoids, while Trichopria and Pachycrepoideus are pupal parasitoids (Stacconi et al. 2013; Daane et al. 2016). Eucoilinae is the largest subfamily with over 1000 identified species, belonging to Figitidae family. Figitid 
wasps are endoparasitoids of dipteran larvae (Buffington and Forshage 2014). Therefore, they play an important role in the management of pests such as tephritid and drosophilid species (Santos et al. 2016).

Having been detected the invasive vinegar fly $D$. suzukii in Turkey in 2014, these natural enemies have become even more important (Orhan et al. 2016). However, neither the natural enemies of Drosophila species nor figitid wasps have been sufficiently studied in Turkey. Only an unpublished paper with respect to the presence of Leptopilina boulardi (Förster) (Hymenoptera: Figitidae) was found in Turkey.

The present study was carried out to determine population dynamics of $D$. suzukii and its associated parasitoids.

\section{Material and methods}

This study was conducted in a 4.7 ha mixed fruit orchard (apple, pear, cherry, plum, grape) located in Uşak, Banaz, Bağkonak village, Turkey ( $\left.38^{\circ} 44^{\prime} 47^{\prime \prime} \mathrm{N}, 29^{\circ} 46^{\prime} 45^{\prime \prime} \mathrm{E}\right)$ in 2017-2018. In order to detect the adult D. suzukii and its parasitoids, the traps used consisted of a plastic bottle of $500 \mathrm{ml}$ containing $100 \mathrm{ml}$ vinegar as attractant for the pest. The bottle was perforated by $5-10$ holes of 3-mm diameter at the top area so that the fruit flies are able to enter into the bottles. The traps were set up at the beginning of April and replaced weekly until mid-December in both years. A total of 4 traps were hung in the study areas every week. Three of the traps were hung on fruit trees (cherry, apple, plum) that were $10 \mathrm{~m}$ apart, while the other trap was in vineyard. The trap catches were collected, filtered, and examined under a binocular microscope. The number of $D$. suzukii and its associated parasitoid species were recorded, and afterward, the parasitoids were kept in $70 \%$ ethyl alcohol for identification process. Furthermore, to determine prevalence of $D$. suzukii throughout Uşak, the traps were placed in 6 districts only once in October of 2018 (Table 1).

The comparison between the fruit trees in terms of the mean catches obtained in 2018, when the present study was carried out was made by applying one-way variance analysis (ANOVA) in SPSS 16.0 software, whereas the comparison between the groups found to

Table 1 Monitoring sites of prevalance of Drosophila suzukii in Uşak, Turkey

\begin{tabular}{llll}
\hline Location & Latitude (N) & Longitude (E) & Fruit \\
\hline Uşak/Çarıkköy & $38^{\circ} 40^{\prime} 42^{\prime \prime}$ & $29^{\circ} 31^{\prime} 31^{\prime \prime}$ & Plum \\
Banaz/Hasanköy & $38^{\circ} 44^{\prime} 58^{\prime \prime}$ & $29^{\circ} 48^{\prime} 10^{\prime \prime}$ & Grape \\
Eşme/Kayapınar & $38^{\circ} 17^{\prime} 27^{\prime \prime}$ & $29^{\circ} 03^{\prime} 22^{\prime \prime}$ & Grape \\
Karahallı/Dumanlı & $38^{\circ} 18^{\prime} 19^{\prime \prime}$ & $29^{\circ} 28^{\prime} 00^{\prime \prime}$ & Grape \\
Sivaslı/Pınarbaşı & $38^{\circ} 28^{\prime} 43^{\prime \prime}$ & $29^{\circ} 40^{\prime} 12^{\prime \prime}$ & Cherry \\
Ulubey/Aşağı & $38^{\circ} 21^{\prime} 55^{\prime \prime}$ & $29^{\circ} 19^{\prime} 32^{\prime \prime}$ & Pear \\
\hline
\end{tabular}

have difference between the mean values was made using Tukey's test at 0.05 significance level.

Figitid species collected in the survey sites were identified by M. Buffington at the Smithsonian Institute in Washington D.C., while pteromalid parasitoids were identified by $M$. Doğanlar at the Biological Control Research Station in Adana.

\section{Results and discussion}

The traps used to monitor the adult population of $D$. suzukii were hung on the trees on April 1 in both years. The numbers of D. suzukii adults caught in the traps are given in Fig. 1. In both years, the first adults detected in the traps were female individuals. In 2017, the first $D$. suzukii adults were captured on September 8, whereas in 2018, they were captured on April 13. The average temperature and relative humidity values in date of first catch was $20^{\circ} \mathrm{C}$ and $39 \%$ R.H. in 2017 and $6{ }^{\circ} \mathrm{C}$ and $80 \%$ R.H. in 2018 (Fig. 2). Likewise, Piotrowski and Łabanowska (2017) reported that the first appearance of $D$. suzukii in 2014 and 2016 was in October and June, respectively. In addition, the first record of D. suzukii in the traps in many European countries including France, Germany, Italy, Poland, and Spain was in October (Calabria et al. 2010; Grassi et al. 2009; Cini et al. 2012; Vogt et al. 2012; Piotrowski and Łabanowska 2017). The highest catches in 2017 and 2018 were recorded as 80 individuals $(33 \hat{\jmath}, 47$ ) $)$ on October 27 and with 605 individuals $(288 \hat{\jmath}, 317$ ) ) on November 17 , respectively. Afterwards, populations of D. suzukii declined sharply by the end of November, when average temperature was below $10{ }^{\circ} \mathrm{C}$. In recent study, D. suzukii populations peaked in late autumn, when the average temperature was below $20{ }^{\circ} \mathrm{C}$ and almost all crops were harvested. Therefore, we suppose that as long as there are natural sources of food in the environment, D. suzukii does not prefer the vinegar traps. Although both female and male individuals were captured from September 2017 and August 2018 to December of all years, the number of females was higher in grand total. In both years, the population density of the pest began to increase from the end of September and fell into a decline from the end of November. A total of 304 traps were hung on during the study and the number of adult flies caught by the traps was 255 in 2017, and 2128 in 2018. Similarly to the first year of this research, Kasap and Özdamar (2019) also reported that the first $D$. suzukii adults were detected in September of all years. Yet, accordingly to Thistlewood et al. (2018), due to the fact that winter of 2017 was warmer than in the previous year, the emergence of adult $D$. suzukii in the latter year occurred earlier than 2017. Also, high population density of D. suzukii in 2018 could be attributed to this situation. D. suzukii was 
2017

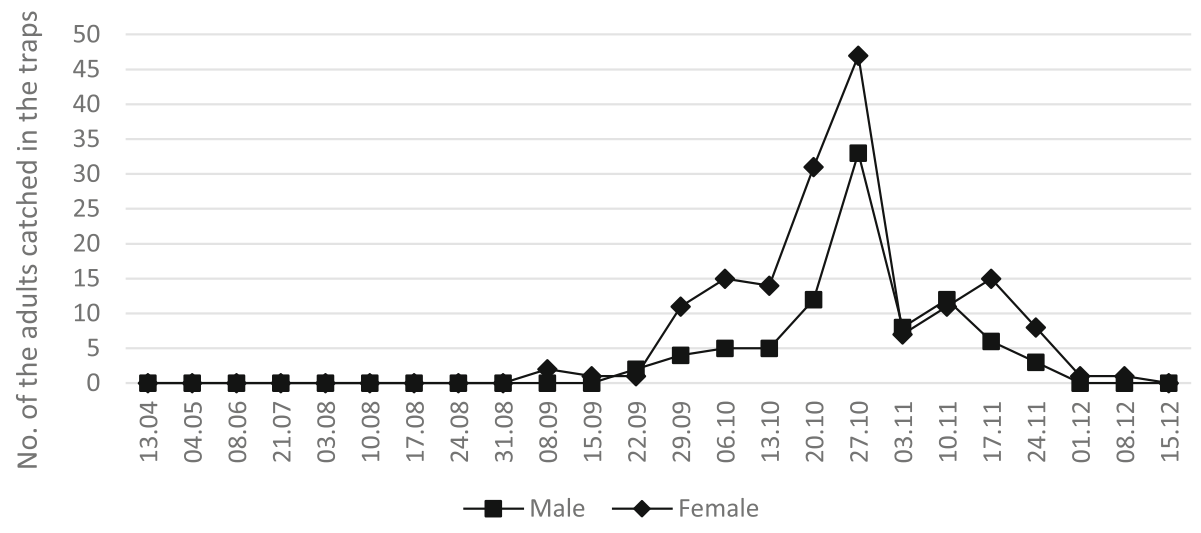

2018

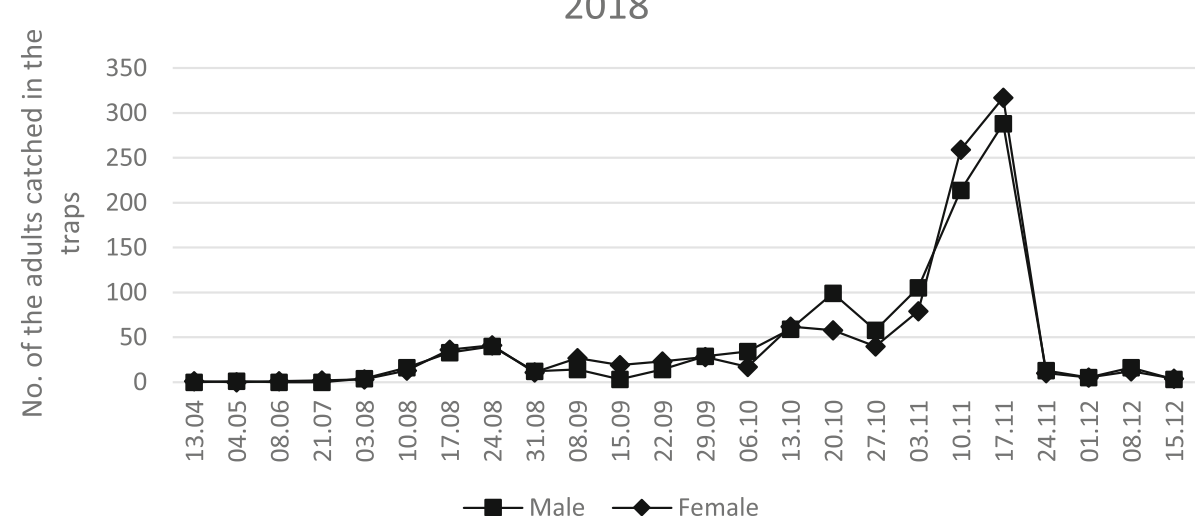

Fig. 1 Adult population dynamic of D. suzukii in Bağkonak village, Banaz, between 2017 and 2018

detected in all the traps deployed at the 6 districts to determine prevalence of the pest.

The numbers of adult $D$. suzukii detected in the traps hung on grape, cherry, apple, and plum trees were compared with each other, and the mean catches on cherry was found significantly higher than the others. Insignificant differences were statistically found between the mean catches in apple and plum trees, while the mean catches in grape differed from those of cherry, apple and plum $(F=1.561 ; \mathrm{df}=3 ; p \leq 0.05)$ (Fig. 3). Extrafloral nectar released by cherry leaves is very important in terms of feeding for adult D. suzukii (Wang et al. 2016). Therefore, the mean catch in cherry was higher for this reason.

A total of 3 parasitoid species of $D$. suzukii were trapped in the bottles. These species were Leptopilina heterotoma (Thomson, 1862); Ganaspis xanthopoda (Ashmead, 1896) (Hymenoptera: Figitade), which are new records for Turkish Eucoilinae fauna; and Pachycrepoideus vindemiae (Rondani, 1875) (Hymenoptera: Pteromalidae).

Both L. heterotoma and G. xanthopoda are minute parasitic wasps, smaller than $2 \mathrm{~mm}$. These species are morphologically very similar to each other. However, $L$. heterotoma is distinguished from G. xanthopoda thanks to some morphological characteristics such as having wings covered with short hair but long at tip (Lue et al. 2016).

Pachycrepoideus vindemiae is a pupal parasitoid, approximately $2-3 \mathrm{~mm}$ in length, attacking more than 60 dipteran species belonging to families Anthomyiidae, Calliphoridae, Drosophilidae, Muscidae, Sarcophagidae, Tachinidae, and Tephritidae (Stacconi et al. 2013). Besides these hosts, Chen et al. (2015) reported that $P$. vindemmiae is a facultative hyperparasitoid of larval parasitoids such as L.heterotoma.

The number of parasitoid individuals in the traps in 2017 and 2018 were 37 and 28, respectively. In 2017, of which 30 individuals were $P$. vindemiae, 6 individuals were L. heterotoma and one individual was G. xanthopoda. Meanwhile, 24 individuals of $P$. vindemiae and 4 individuals of L. heterotoma were trapped in 2018. No parasitoid species was encountered in the traps until July 2017, when L. heterotoma was detected, whereas one individual of $P$. vindemiae was detected as first parasitoid species in June 2018. P. vindemiae was found in the 

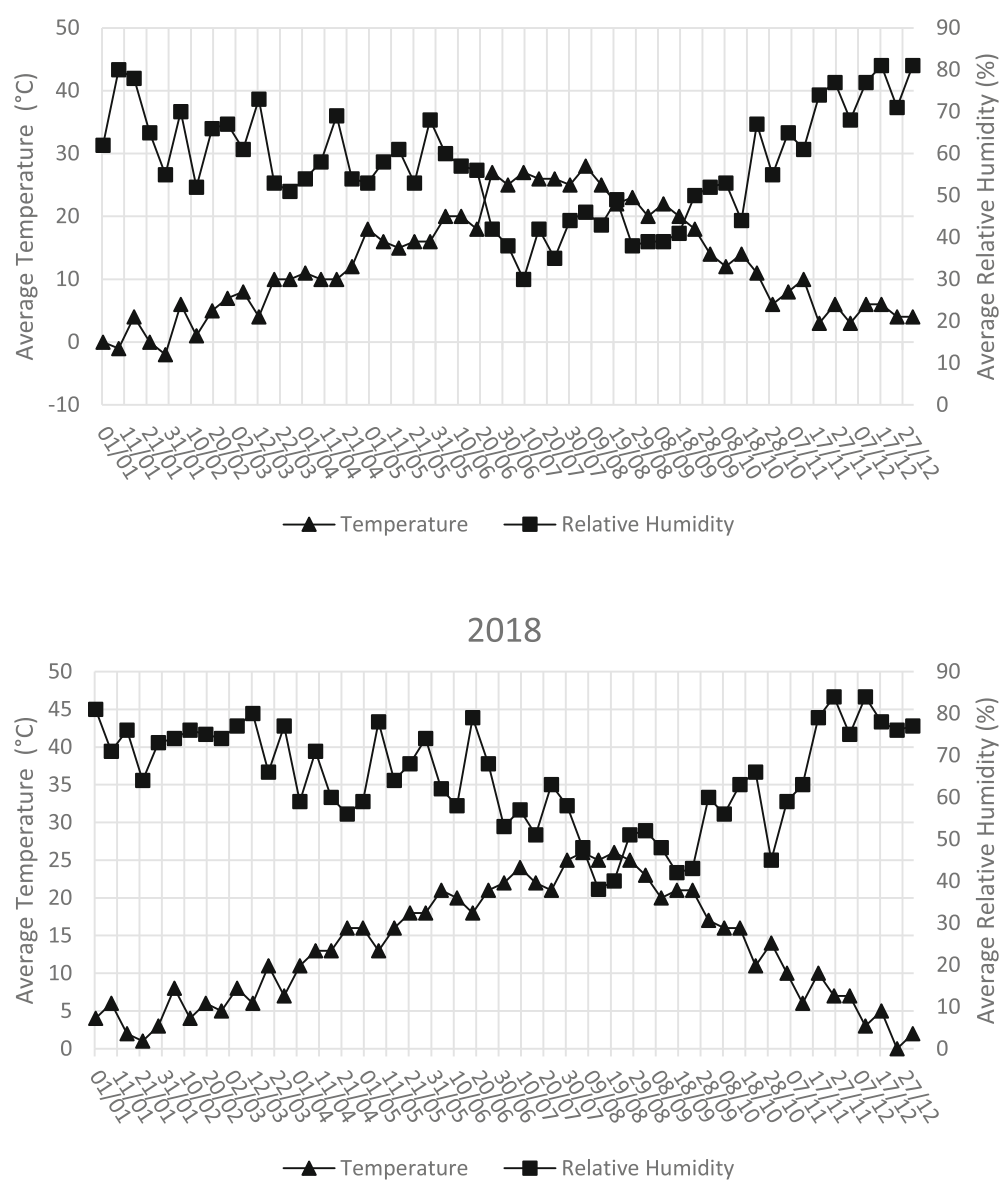

Fig. 2 The average temperature and relative humidity values in Banaz district in 2017-2018

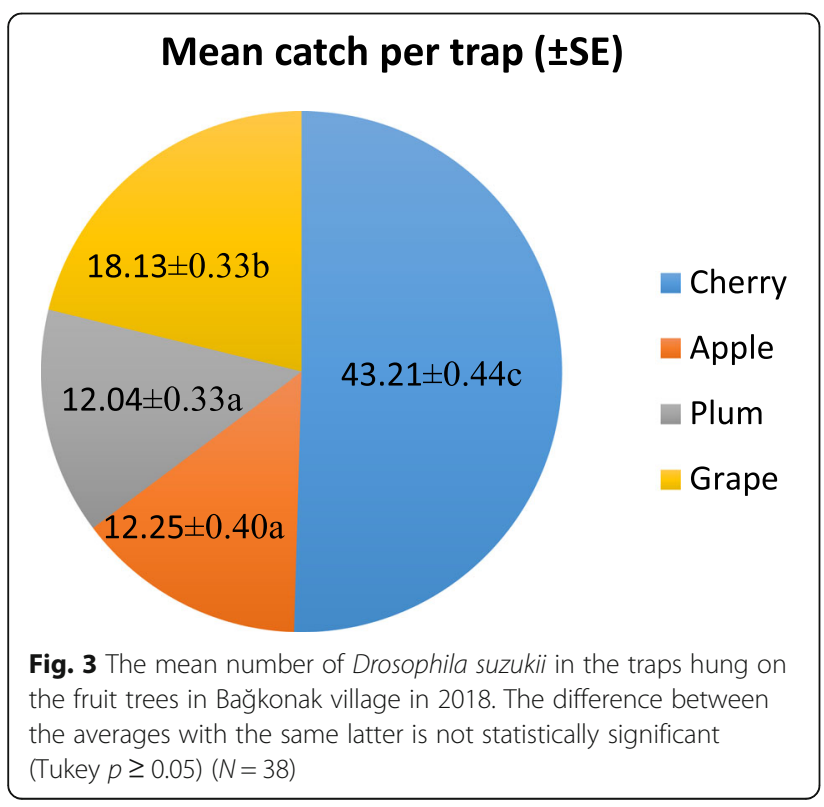

traps placed in September and October in 2017, while it was found in June, August, September, and October in 2018. Population of $P$. vindemiae peaked in October of both years. Ganaspis xanthopoda was only detected in October of 2017.

Almost all parasitoid species were collected in September and October of both years, when average temperature was $20^{\circ} \mathrm{C}$ and $13{ }^{\circ} \mathrm{C}$, respectively. Approximately $81 \%$ of the parasitoids obtained in 2017 and $86 \%$ in 2018 was $P$. vindemiae, which is an idiobiont pupal ectoparasitoid. Also, these results were consistent with those of Batsey et al. (2015). In contrast, Wang et al. (2016) reported that they detected two parasitoid species of D. suzukii but did not encounter $P$. vindemiae. While G. xanthopoda and $L$. heterotoma were only detected in traps installed in Bağkonak, P. vindemiae was found in the traps in both Bağkonak and the other districts where the traps were installed to determine prevalence of $D$. suzukii.

Although $P$. vindemiae was the most abundant and prevalent parasitoid species detected in traps placed during the study, it has not been considered to be a suitable 
biological control agent for $D$. suzukii management due to having a wide range of host. Nevertheless, since $P$. vindemmiae is widespread all over the world and is able to successfully parasitize $D$. suzukii, it has become an important natural enemy against the invasive spotted wing drosophila especially in areas newly invaded (Chen et al. 2015).

On the other hand, G. xanthopoda was found by one individual in 304 material examined. It prefers $D$. suzukii as host (Stacconi et al. 2013). In addition, Kasuya et al. (2013) pointed out that this species has the highest rates of D. suzukii parasitism. Chabert et al. (2012) detected that $L$. heterotoma was able to parasitize $95 \%$ of larvae of $D$. suzukii under laboratory conditions.

During the study, in addition to D. suzukii and its attracted parasitoids, other Drosophilidae species including $D$. melanogaster Meigen, D. subobscura Collin, D. simulans Sturtevant, D. busckii Cocquillett, D. immigrans Sturtevant, Gitona distigma Meigen, Zaprionus tuberculatus Malloch, and Hirtodrosophila cameraria Haliday were also trapped.

Harmful species, new for the region, have caused massive damage to cultivated areas because of the absence of their natural enemies. It takes time for natural enemies to pose impact on hosts in such areas. Therefore, indigenous natural enemies have been acknowledged as one of the most important component in biological control programs, because indigenous natural enemies may suppress a new pest more efficiently than imported natural enemies (Urbaneja et al. 2000). Also, control techniques against new pest can be successfully and effectively conducted in areas where their natural enemies are already present.

\section{Conclusion}

In conclusion, 3 parasitoid species of $D$. suzukii, the new invasive species in Turkey, were firstly detected in the present study. Although detection of G. xanthopoda and $L$. heterotoma seems to be promising in terms of biological control, the population density of the species was fairly low. However, it has been considered that their role may increase in time with some protective and supportive practices such as a good agriculture practice are followed. Also, further studies on the efficacy of these parasitoids and may be more should be considered.

\footnotetext{
Acknowledgments

We are grateful to Dr Matthew L. Buffington (National Museum of Natural History, Smithsonian Institution, Washington, DC, USA) for the identification of the figitid species, to Prof Dr Mikdat Doğanlar (Biological Control Research Station, Adana, Turkey) for the identification of the pteromalid species, and to Dr Paul Beuk (Maastricht Natural History Museum, Maastricht, Netherlands) for the identification of the Drosophila species.
}

\section{Authors' contributions}

EZ and IK designed the experiments. EZ carried out the study and wrote the manuscript. İK supervised the manuscript. Both authors read and approved the final manuscript
Funding

Not applicable

Availability of data and materials

All data generated or analyzed during this study are included in this manuscript.

\section{Ethics approval and consent to participate}

Not applicable

\section{Consent for publication}

Not applicable

\section{Competing interests}

The authors declare that they have no competing interests.

\section{Author details}

'Directorate of Provincial Agriculture and Forestry, 64100 Uşak, Turkey.

${ }^{2}$ Faculty of Agriculture, Department of Plant Protection, Isparta University of Applied Sciences, 32100 Isparta, Turkey.

Received: 15 March 2019 Accepted: 20 June 2019

Published online: 01 July 2019

\section{References}

Batsey M, Anfora G, Buffington M, Daane KM, Dalton DT, Holmer KM, Stacconi MVR, Grassi A, loriatti C, Loni A, Miller JC, Ountar M, Wang X, Wiman NG, Walton VM (2015) Seasonal occurrence of resident parasitoids associated with Drosophila suzukii in two small fruit production regions of Italy and the USA. Bull Insectol 68(2):255-263

Buffington ML, Forshage M (2014) The description of Garudella Buffington and Forshage, new genus (Hymenoptera: Figitidae: Eucoilinae). Proceed Entomol Soc Washington 116:225-242

Calabria G, Máca J, Bächli G, Serra L, Pascual M (2010) First records of the potential pest species Drosophila suzukii (Diptera: Drosophilidae) in Europe. J Appl Entomol 136:139-147

Chabert S, Allemanda R, Poyetab M, Eslinb P, Gibert P (2012) Ability of European parasitoids (Hymenoptera) to control a new invasive Asiatic pest, Drosophila suzukii. Biol Control 63:40-47

Chen W, He Z, Ji XL, Tang ST, Hu HY (2015) Hyperparasitism in a generalist ectoparasitic pupal parasitoid, Pachycrepoideus vindemmiae (Hymenoptera: Pteromalidae), on its own conspecifics: when the lack of resource lead to cannibalism. Plos One 10(4):e0124305

Cini A, loriatti C, Anfora G (2012) A review of the invasion of Drosophila suzukii in Europe and a draft research agenda for integrated pest management. Bull Insectol 65:149-160

Daane KM, Wang XG, Biondi A, Miller B, Miller JC, Riedl H, Shearer PW, Guerrieri E, Giorgini M, Buffington M, Van-Achterberg K, Song Y, Kang T, Yi H, Jung C, Lee DW, Chung BK, Hoelmer KA, Walton VM (2016) First exploration of parasitoids of Drosophila suzukii in South Korea as potential classical biological agents. J Pest Sci 89:823-835

De Ros G, Anfora G, Grassi A, loriatti C (2013) The potential economic impact of Drosophila suzukii on small fruits production in Trentino (Italy). lobc Wprs Bull 91:317-321

Efil L (2018) Çanakkale ili çilek alanlarında yeni bir zararlı Drosophila suzukii (Matsumura) (Diptera: Drosophilidae)'nin yaylıı̧ alanları ve bulaşıklılığı. Türk Tarım ve Doğa Bilimleri Dergisi 5(3):280-284

Grassi A, Palmieri L, Giongo L (2009) Drosophila (Sophophora) suzukii (Matsumura) new pest of small fruit crops in Trentino (in Italian). Terra Trentina 10:19-23

Haye T, Girod P, Cuthberstson AGS, Wang XG, Daane KM, Hoelmer K, Baroffio C, Zhang J, Desneux N (2016) Current SWD IPM tactics and their practical implementation in fruit crops across different regions around the world. J Pest Sci 89:643-651

loriatti C, Walton V, Dalton D, Anfora G, Grassi A, Maistri S, Mazzoni V (2015) Drosophila suzukii (Diptera: Drosophilidae) and its potential impact to wine grapes during harvest in two cool climate wine grape production regions. J Econ Entomol 108:1148-1155

Kasap I, Özdamar E (2019) Population development of Drosophila suzukii (Matsumura) (Diptera:Drosophilidae) in vineyards of Çanakkale province. Turk J Entomol 41(3):57-62 
Kasuya N, Mitsui H, Ideo S, Watada M, Kimura MT (2013) Ecological, morphological and molecular studies on Ganaspis individuals (Hymenoptera: Figitidae) attacking Drosophila suzukii (Diptera: Drosophilidae). Appl Entomol Zool 48:87-92

Lee JC, Dreves AJ, Cave AM, Kawai S, Isaacs R, Miller JC, Van Timmeren S, Bruck DJ (2015) Infestation of wild and ornamental noncrop fruits by Drosophila suzukii (Diptera: Drosophilidae). Ann Entomol Soc Am 108(2):117-129

Lue CH, Driskell AC, Leips J, Bufington M (2016) Review of the genus Leptopilina (Hymenoptera, Cynipoidea, Figitidae, Eucoilinae) from the Eastern United States, including three newly described species. J Hymenoptera Res 53:35-76

Orhan A, Aslantaş R, Önder BŞ, Tozlu G (2016) First record of the invasive vinegar fly Drosophila suzukii (Matsumura) (Diptera: Drosophilidae) from eastern Turkey. Turkish J Zool 40:290-293

Piotrowski W, Łabanowska BH (2017) Drosophila suzukii new pest in Poland. Integ Protec Fruit Crops IOBC-WPRS Bull 123:165-170

Santos WGN, Fernandes EC, Souza MM, Guimaraes JA, Araujo EL (2016) First record of Eucoilinae (Hymenoptera: Figitidae), parasitoids of African fig fly Zaprionus indianus Gupta (Diptera: Drosophilidae), in the Caatinga biome. Semina: Ciencias Agrarias 37:3055-3058

Stacconi MVR, Grassi A, Dalton DT, Miller B, Ouantar M, Loni A, loriatti C, Walton VM, Anfora G (2013) First field records of Pachycrepoideus vindemiae as a parasitoid of Drosophila suzukii in European and Oregon small fruit production areas. Entomologia 1:11-16

Thistlewood HMA, Gill P, Beers EH, Shearer PW, Walsh DB, Rozema BM, Acheampong S, Castagnoli S, Yee WL, Smytheman P, Whitener AB (2018) Spatial analysis of seasonal dynamics and overwintering of Drosophila suzukii (Diptera: Drosophilidae) in the Okanagan-Columbia Basin, 2010-2014. Environ Entomol 47(2):221-232

Urbaneja A, Llacer E, Tomas O, Garrido A, Jacas JA (2000) Indigenous natural enemies associated with Phyllocnistis citrella (Lepidoptera: Gracillariidae) in Eastern Spain. Biol Control 18:199-207

Vogt H, Baufeld P, Gross J, Kopler K, Hoffmann C (2012) Drosophila suzukii: a new threat feature for the European fruit and viticulture report for the international conference in Trient, 2, December 2011. J Fur Kulturpflanzen 64:68-72

Walsh DB, Bolda MP, Goodhue RE, Dreves AJ, Lee J, Bruck DJ, Walton VM, O'Neal SD, Zalom FG (2011) Drosophila suzukii (Diptera : Drosophilidae) : invasive pest of ripening soft fruit expanding its geographic range and damage potential. J Integrated Pest Manag 2(1):1-7

Wang XG, Stewart TJ, Biondi A, Chavez BA, Ingels C, Caprile J, Grant JA, Walton VM, Daane KM (2016) Population dynamics and ecology of Drosophila suzukii in Central California. J Pest Sci 89:701-712

Yu D, Zalom FG, Hamby KA (2013) Host status and fruit odor response of Drosophila suzukii (Diptera: Drosophilidae) to figs and mulberries. J Econ Entomol 106:1932-1937

\section{Publisher's Note}

Springer Nature remains neutral with regard to jurisdictional claims in published maps and institutional affiliations.

\section{Submit your manuscript to a SpringerOpen ${ }^{\circ}$ journal and benefit from:}

- Convenient online submission

- Rigorous peer review

- Open access: articles freely available online

- High visibility within the field

- Retaining the copyright to your article

Submit your next manuscript at $\boldsymbol{\nabla}$ springeropen.com 